\title{
The Prevalence of Familial Mediterranean Fever and Behçet's Disease: A Cross-Sectional Study
}

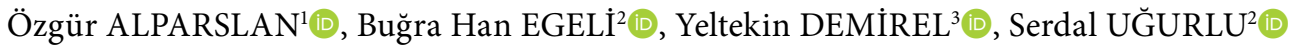 \\ ${ }^{1}$ Division of Midwifery, Gaziosmanpasa University, Faculty of Health Sciences, Tokat, Turkey \\ ${ }^{2}$ Department of Internal Medicine, Division of Rheumatology, Istanbul University, Cerrahpaşa Medical Faculty, Istanbul, Turkey \\ ${ }^{3}$ Department of Family Medicine, Sivas Cumhuriyet University Medicine Faculty, Sivas, Turkey
}

\begin{abstract}
Objectives: This study aims to investigate the coexistence of familial Mediterranean fever (FMF) and Behçet's disease (BD).

Patients and methods: This cross-sectional study was conducted between May 2009 and August 2009. The study included 14,881 randomized children (7,741 males, 7,140 females; mean age 13.0 years; range, 12 to 14 years) from sixth to eighth grades, in 72 primary schools in the center of Turkey's Sivas province. Of these children, 985 were randomly selected and interviewed with their parents. During these interviews, the family trees up to second-degree relatives were drawn. The presence of a diagnosis of FMF or BD was questioned. Patient history, physical examination, eye examination, and pathergy test were performed when needed. The methods of this study were reported in accordance with the STrengthening the Reporting of OBservational studies in Epidemiology guidelines.

Results: Nine hundred and eighty-five students, 978 mothers, 953 fathers, and 1,876 relatives (4,792 in total) were included in the study. The ratio of consanguineous marriage ratio was $13.6 \%$. Only 30 patients $(0.6 \%)$ were diagnosed with FMF, while three $(0.06 \%)$ were diagnosed with BD. In patients with FMF, consanguineous marriage was statistically significant $(p=0.015)$. In terms of low back, heel, and joint pain and morning stiffness, there was a statistically significant difference between patients with and without FMF ( $p<0.05)$. Of the three BD patients, one had concomitant FMF. Conclusion: The prevalence of FMF in Sivas province was higher than Turkey's prevalence; however, the prevalence of BD was lower. According to these findings, it is not easy to conclude that the two diseases share a common pathogenesis.

Keywords: Behçet's disease, epidemiology, familial Mediterranean fever.
\end{abstract}

Familial Mediterranean fever (FMF) is an autoinflammatory disease characterized by peritonitis, arthritis, pleural effusion, and erysipelas-like erythema. Its etiology is known to be genetic with pathogenic mutations located on the short arm of chromosome 16p13.3. Another clinical entity, Behçet's disease (BD), is a multisystemic disease characterized by recurrent oral aphthous ulcers, skin lesions, arthritis, uveitis, thrombophlebitis, and gastrointestinal and central nervous system complications. The etiology of $\mathrm{BD}$ is not completely understood, while the underlying pathogenesis is vasculitis. It is associated with environmental factors and the human leukocyte antigen (HLA)-B51 gene or its split HLA-B51 antigen. Mendelian inheritance was not shown ${ }^{1}$ unlike FMF being autosomal recessive.

Familial Mediterranean fever and BD are two distinct diseases; however, they share numerous clinical features. During the prognosis of FMF, patients can develop muscle pain, febrile scrotal attacks, polyarteritis nodosa (PAN), and

Received: August 23, 2019 Accepted: February 26, 2020 Published online: July 20, 2020

Correspondence: Serdal Uğurlu, MD. İstanbul Üniversitesi Cerrahpaşa Tıp Fakültesi İç Hastalıkları Anabilim Dalı, Romatoloji Bilim Dalı, 34098 Fatih, İstanbul, Türkiye. Tel: +90 542 - 4356265 e-mail: serdalugurlu@gmail.com

\section{Citation:}

Alparslan Ö, Egeli BH, Demirel Y, Ugurlu S. The Prevalence of Familial Mediterranean Fever and Behçet's Disease: A Cross-Sectional Study. Arch Rheumatol 2020;35(4):609-613. 
Henoch-Schönlein purpura (HSP)-like vasculitides hinting clinical manifestations of BD. In 2005, Turkish FMF Working Group's study showed that $93.7 \%$ of FMF cases are characterized with peritonitis, $92.5 \%$ with fever, $47.4 \%$ with arthritis, $31.2 \%$ with pleuritis, $39.6 \%$ with myalgia, $20.9 \%$ with erysipelas-like rash, $12.9 \%$ with amyloidosis, $0.9 \%$ with PAN, $2.7 \%$ with HSP, and $1.4 \%$ with pericarditis. ${ }^{2}$ There are case reports presenting FMF-BD coexistence. ${ }^{3}$ FMF-BD coexistence can be seen as FMF with oral aphthous ulcers, aseptic meningitis, and skin manifestations; or as $\mathrm{BD}$ with peritonitis and pleuritis. ${ }^{4}$

Another factor showing the potential association is epidemiologic studies, particularly on geographic distributions. FMF is very prevalent in Mediterranean countries (in Arabic, Turkish, Armenian and Sephardi Jew populations). The prevalence is $1 / 1,000$ among Turks, $1 / 500$ among Armenians, and 1/73,000 in Ashkenazi Jews. In Turkey, FMF is more common in the central region. $\mathrm{BD}$ is more common along the Silk Road, starting from the Mediterranean to the Far East. Along this route, it is most common in Turkey. In Turkey, the prevalence of $\mathrm{BD}$ has been published as 110-420 in 100,000 adult patients. ${ }^{5-9}$ Till now, the highest prevalence ratio was found in Istanbul as 42/10,000. ${ }^{9}$ Iran, Japan, Korea, China, and Tunisia are the other BD prevalent countries. ${ }^{10}$ In Japan, the prevalence was found to be $13-20 / 100,000 .{ }^{11} \mathrm{BD}$ is more frequent in FMF patients than it is in the general population. Schwartz et al. ${ }^{12}$ found the frequency of FMF-BD as 39/4,000. HLA-B51 frequency in FMF-BD patients and their relatives was $53 \%$ and $50 \%$, respectively.

The coexistence and common clinical features of FMF and BD can hint at a common pathogenesis or can be related to coincidental geographical distribution. Studies by Schwartz et al. ${ }^{12}$ and Birlik et al. ${ }^{13}$ including both clinical and genetic aspects suggested a common etiopathogenesis. Nevertheless, Ben-Chetrit et al. ${ }^{14}$ could not find any increased association in patients with heterozygous MEFV mutations compared to no MEFV mutation at all. Genetic studies claim a causal association between the two diseases. Imirzalioglu et al. ${ }^{15}$ found FMF-related MEFV gene mutation frequency in BD patients as 36\% and stated the presence of MEFV mutations in the pathogenesis of $\mathrm{BD}$. On the other hand, data from a study of Watad et al. ${ }^{16}$ imply that the difference between BD and FMF cannot be neglected.

Even though there are prevalence studies of FMF in prevalent locations of Turkey, to our knowledge, BD prevalence or FMF-BD coexistence were never studied in these locations. In Sivas, a FMF-prevalent province in the central region of Turkey, FMF prevalence was found to be 250/105..$^{1,2}$ Therefore, in this study, we aimed to investigate the coexistence of FMF and $\mathrm{BD}$.

\section{PATIENTS AND METHODS}

This cross-sectional study was conducted at Cumhuriyet University Faculty of Medicine between May 2009 and August 2009. The study included 14,881 randomized children (7,741 males, 7,140 females; mean age 13.0 years; range, 12 to 14 years) from sixth to eighth grades, in 72 primary schools in the center of Turkey's Sivas province. Of these children, 985 were randomly selected and interviewed with their parents. During these interviews, the family trees up to second-degree relatives were drawn. Of all subjects, those with a possible or known FMF or $\mathrm{BD}$ diagnosis were questioned with an additional form. The study protocol was approved by the Provincial National Education Directorate and the Provincial Health Directorate. A written informed consent was obtained from the mother of each patient. The study was conducted in accordance with the principles of the Declaration of Helsinki.

Every known diagnosis stated by the family was confirmed by a tertiary center. Those with a possible diagnosis were further investigated at Cumhuriyet University Medical Faculty Family Medicine Unit. For each disease, a disease-related history was followed by physical examination, while eye examination and pathergy tests were performed for $\mathrm{BD}$ when needed. All patients were diagnosed according to the International Study Group criteria for the diagnosis of BD, and Tel-Hashomer criteria for the diagnosis of FMF. ${ }^{17,18}$

Neither blood tests nor any imaging studies were ordered. No drugs were used in our study. Inclusion criteria were mothers older than 18 years and subjects with informed consent.

The methods of this study were designed to comply with the STrengthening the Reporting 


\begin{tabular}{|l} 
Table 1. Familial Mediterranean fever symptoms in participants with and without FMF \\
diagnosis
\end{tabular}

of OBservational studies in Epidemiology guidelines. ${ }^{19}$ A total of 4,792 subjects were screened to detect prevalence with an error of $0.35 \%$ and $95 \%$ confidence interval. Clinical features of FMF diagnosis were also noted to understand the patient profile better.

\section{Statistical analysis}

The SPSS for Windows version 14.0 software (SPSS Inc., Chicago, IL, USA) was used for recording and analysis purposes. In statistical evaluation, the data were presented as mean \pm standard deviation and percentage. Descriptive statistics were used to describe the basic features of the data in the study. Shapiro-Wilk normality test was used for evaluating the normality in the distribution of numeric variables. The Student's t-test was used for the analysis of parametric data with normal distribution, while the Mann-Whitney U test was used for those without normal distribution. The Chi-square test was used for comparing data in groups and evaluation was performed with Fischer's exact test. $\mathrm{P}<0.05$ was accepted as statistically significant.

\section{RESULTS}

The ratio of consanguineous marriage was $13.6 \%(\mathrm{n}=650)$. Only 30 subjects $(0.6 \%)$ were diagnosed with FMF, while three $(0.06 \%)$ were diagnosed with $\mathrm{BD}$. When FMF symptoms were questioned, $7.8 \%(n=376)$ complained of low back pain, $6.7 \%(n=322)$ of fever in the past year, 3.6\% $(n=173)$ of morning stiffness, $3.2 \%(n=153)$ of heel pain, $2.8 \%(n=136)$ of joint pain, and $2.4 \%$ $(\mathrm{n}=115)$ of abdominal pain (Table 1$)$. The ratios of low back, heel, and joint pain and morning stiffness were significantly higher in patients with FMF $(p<0.05)$.

No significant difference was found between sexes of FMF patients. In patients with FMF, the

Table 2. Sex and consanguineous marriage ratios

\begin{tabular}{|c|c|c|c|c|c|}
\hline & \multicolumn{4}{|c|}{ FMF diagnosis } & \multirow[b]{3}{*}{$p$} \\
\hline & \multicolumn{2}{|c|}{ Yes } & \multicolumn{2}{|c|}{ No } & \\
\hline & $\mathrm{n}$ & $\%$ & $\mathrm{n}$ & $\%$ & \\
\hline \multicolumn{6}{|l|}{ Sex } \\
\hline Male & 15 & 50.0 & 2304 & 48.4 & \multirow{2}{*}{0.86} \\
\hline Female & 15 & 50.0 & 2458 & 51.6 & \\
\hline \multicolumn{6}{|c|}{ Consanguineous marriage } \\
\hline Present & 9 & 30.0 & 641 & 13.5 & \multirow{2}{*}{0.02} \\
\hline Absent & 21 & 70.0 & 4121 & 86.5 & \\
\hline
\end{tabular}


consanguineous marriage ratio was statistically significant $(p=0.02)$ (Table 2).

Three patients were diagnosed with $\mathrm{BD}$ among the FMF population. Only one patient was also diagnosed with FMF. The mean age of the $\mathrm{BD}$ patients was 31.67 years (13, 23, and 59 years). The patient with BD and FMF was male and 23 years old. The other two patients were female.

\section{DISCUSSION}

In this cross-sectional study of 4,792 participants, $\mathrm{BD}$ prevalence was found to be very low unlike the prevalence of FMF, which was found to be higher than Turkey's prevalence. Only one $\mathrm{BD}$ patient had a concomitant FMF diagnosis. The ratio of consanguineous marriage was found to be significantly higher among FMF patients.

Particularly affecting human populations in the Mediterranean and Middle Eastern regions, FMF is frequently seen in Turkish, Jewish, Arabic, and Armenian societies. The prevalence of FMF in different studies in Turkey was found between $0.003-0.82 \% .^{3,4,20,21}$ A study conducted by Kisacik et al. $^{22}$ demonstrated the FMF prevalence in Tokat province as $0.82 \%$, which was higher than any other province in Turkey. ${ }^{1-4,20,21}$ In our study, FMF prevalence was found as $0.6 \%$. This ratio was above Turkey's overall mean. In a study of Onen et al. ${ }^{23}$ which was conducted in the Sivas province, FMF prevalence was found as $0.25 \%$, which was much lower than our result.

In Turkey, the prevalence of $\mathrm{BD}$ has been published as $110-420$ in 100,000 adult patients. ${ }^{5-8,23} \mathrm{BD}$ prevalence among FMF patients has been claimed to be higher than the general population. In a study of Schwartz et al., ${ }^{12}$ out of 4,000 FMF patients, 39 were also diagnosed with BD. Sivas province was selected purposefully for our study, with the expectation of a high $\mathrm{BD}$ prevalence due to an evident high FMF prevalence. Nonetheless, $\mathrm{BD}$ prevalence was found to be $0.06 \%(n=3 / 4,792)$.

Birlik et al. ${ }^{13}$ stated the possibility of a common mechanism of pathogenesis in FMF and BD cases. In our FMF positive group, BD frequency was higher than the FMF negative group $(p=0.02)$. In 30 patients with FMF, one patient was also diagnosed with $\mathrm{BD}$. These findings are in accordance with the findings of Schwartz et al. ${ }^{12}$ A mutation analysis study by Livneh et al. ${ }^{24}$ also argued that comorbid cases with only a single mutation in the MEFV coding region may be adequate for FMF expression.

Even though Sivas is a high prevalence location for both diseases, low coexistence found in this study disproves a geographical theory behind the coexistence of these two diseases. Also, it is not easy to conclude that these two diseases share a common pathogenesis. Knowing the fact that FMF has numerous comorbidities of inflammatory diseases like spondyloarthritis, multiple sclerosis, ulcerative colitis, and various systemic vasculitides, ${ }^{25} \mathrm{BD}$ is likely to be another example rather than being an association.

Regarding the study limitations, lack of genetic analysis hinders reaching a conclusion on etiopathogenesis-related association of the two diseases. Nevertheless, since these diseases have a specific geographical distribution, a prevalence study of a high prevalence location can hint at inconsistency. In addition, we already are aware of the genetic phenotype of Sivas province. Therefore, studying the genetic information of these patients were found unneccessary since we know that they wouldn't be different from what we know so far from Turkish epidemiological data. ${ }^{26}$ Another limitation is the age groups. The mean age of diagnosis of the two diseases are different as BD is usually diagnosed significantly later than FMF at the mean age of 28.71 years in Southeastern Turkey. ${ }^{27}$ As we examined secondary school students, longer follow-up is required to correctly define $\mathrm{BD}$ prevalence. Moreover, response bias is likely with our study since, based on our clinical experience, we know that families tend to hide their FMF disease due to stigmatism and this probably underestimated the FMF prevalence.

In conclusion, Sivas is a province in Turkey where FMF prevalence is much higher than Turkey's overall mean. Our study demonstrated that the prevalence was much higher than the reported statistics in Sivas in terms of FMF. Nevertheless, our results on the prevalence of $\mathrm{BD}$ were much lower than the previously reported rates. If any common pathogenesis existed in FMF and $\mathrm{BD}$ cases, we would have found higher $\mathrm{BD}$ prevalence in this region. However, we did not reach such a conclusion. 


\section{Declaration of conflicting interests}

The authors declared no conflicts of interest with respect to the authorship and/or publication of this article.

\section{Funding}

This study was funded by Cumhuriyet University Research Funding No. SYO-4,2007.

\section{REFERENCES}

1. Ozen S, Karaaslan Y, Ozdemir O, Saatci U, Bakkaloglu A, Koroglu E, et al. Prevalence of juvenile chronic arthritis and familial Mediterranean fever in Turkey: a field study. J Rheumatol 1998;25:2445-9.

2. Tunca M, Akar S, Onen F, Ozdogan H, Kasapcopur $\mathrm{O}$, Yalcinkaya F, et al. Familial Mediterranean fever (FMF) in Turkey: results of a nationwide multicenter study. Medicine (Baltimore) 2005;84:1-11.

3. Frigui M, Kechaou M, Jallouli M, Kaddour N, Chaabouni HB, Bahloul Z. Coexistence of Behçet's disease with ankylosing spondylitis and familial Mediterranean fever: a rare occurrence. Clin Pract 2011;1:e34.

4. Marshall SE. Behçet's disease. Best Pract Res Clin Rheumatol 2004;18:291-311.

5. Yurdakul S, Yazici H. Behçet's syndrome. Best Pract Res Clin Rheumatol 2008;22:793-809.

6. Demirhindi O, Yazıcı H, Binyıldız P, Dayığlu N, Tüzün Y, Altaç M, et al. Silivri Fener köyü ve yöresinde Behçet Hastalığı sıklığı ve bu hastalığın toplum içinde taranmasında kullanılabilecek bir yöntem. Cerrahpaşa Tip Fak Derg 1981;12:509-14.

7. Yurdakul S, Günaydin I, Tüzün Y, Tankurt N, Pazarli $\mathrm{H}$, Ozyazgan $\mathrm{Y}$, et al. The prevalence of Behçet's syndrome in a rural area in northern Turkey. J Rheumatol 1988;15:820-2.

8. Idil A, Gürler A, Boyvat A, Caliskan D, Ozdemir $\mathrm{O}$, Isik A, et al. The prevalence of Behçet's disease above the age of 10 years. The results of a pilot study conducted at the Park Primary Health Care Center in Ankara, Turkey. Ophthalmic Epidemiol 2002;9:325-31.

9. Cakir N, Dervis E, Benian O, Pamuk ON, Sonmezates $\mathrm{N}$, Rahimoglu R, et al. Prevalence of Behçet's disease in rural western Turkey: a preliminary report. Clin Exp Rheumatol 2004;22:S53-5.

10. Azizlerli G, Köse AA, Sarica R, Gül A, Tutkun IT, Kulaç $M$, et al. Prevalence of Behçet's disease in Istanbul, Turkey. Int J Dermatol 2003;42:803-6.

11. Sakane T, Takeno M, Suzuki N, Inaba G. Behçet's disease. N Engl J Med 1999;341:1284-91.

12. Schwartz T, Langevitz P, Zemer D, Gazit E, Pras M, Livneh A. Behçet's disease in Familial Mediterranean fever: characterization of the association between the two diseases. Semin Arthritis Rheum 2000;29:286-95.
13. Birlik M, Tunca M, Hizli N, Soytürk M, Yeniçerioğlu Y, Ozcan MA, et al. Coexistence of familial Mediterranean fever with sacroiliitis and Behçet's disease: a rare occurrence. Clin Rheumatol 1998;17:397-9.

14. Ben-Chetrit E, Cohen R, Chajek-Shaul T. Familial mediterranean fever and Behçet's disease--are they associated? J Rheumatol 2002;29:530-4.

15. Imirzalioglu N, Dursun A, Tastan B, Soysal Y, Yakicier MC. MEFV gene is a probable susceptibility gene for Behçet's disease. Scand J Rheumatol 2005;34:56-8.

16. Watad A, Tiosano S, Yahav D, Comaneshter D, Shoenfeld Y, Cohen AD, et al. Behçet's disease and familial Mediterranean fever: Two sides of the same coin or just an association? A cross-sectional study. Eur J Intern Med 2017;39:75-8.

17. Criteria for diagnosis of Behçet's disease. International Study Group for Behçet's Disease. Lancet 1990;335:1078-80.

18. Livneh A, Langevitz P, Zemer D, Zaks N, Kees $\mathrm{S}$, Lidar $\mathrm{T}$, et al. Criteria for the diagnosis of familial Mediterranean fever. Arthritis Rheum 1997;40:1879-85.

19. Cuschieri S. The STROBE guidelines. Saudi J Anaesth 2019;13:S31-S4.

20. Cobankara V, Fidan G, Türk T, Zencir M, Colakoglu $\mathrm{M}$, Ozen S. The prevalence of familial Mediterranean fever in the Turkish province of Denizli: a field study with a zero patient design. Clin Exp Rheumatol 2004;22:S27-30.

21. Ozdemir AI, Sokmen C. Familial Mediterranean fever among the Turkish people. Am J Gastroenterol 1969;51:311-6.

22. Kisacik B, Yildirim B, Tasliyurt T, Ozyurt H, Ozyurt $B$, Yuce $S$, et al. Increased frequency of familial Mediterranean fever in northern Turkey: a populationbased study. Rheumatol Int 2009;29:1307-9.

23. Onen F, Sumer H, Turkay S, Akyurek O, Tunca $\mathrm{M}$, Ozdogan $\mathrm{H}$. Increased frequency of familial Mediterranean fever in Central Anatolia, Turkey. Clin Exp Rheumatol 2004;22:S31-3.

24. Livneh A, Aksentijevich I, Langevitz P, Torosyan Y, G-Shoham N, Shinar Y, et al. A single mutated MEFV allele in Israeli patients suffering from familial Mediterranean fever and Behçet's disease (FMF-BD). Eur J Hum Genet 2001;9:191-6.

25. Ozen S. Mutations/polymorphisms in a monogenetic autoinflammatory disease may be susceptibility markers for certain rheumatic diseases: lessons from the bedside for the benchside. Clin Exp Rheumatol 2009;27(2 Suppl 53):S29-31.

26. Atagunduz P, Ergun T, Direskeneli H. MEFV mutations are increased in Behçet's disease (BD) and are associated with vascular involvement. Clin Exp Rheumatol 2003;21:S35-7.

27. Sula B, Batmaz I, Ucmak D, Yolbas I, Akdeniz S. Demographical and Clinical Characteristics of Behcet's Disease in Southeastern Turkey. J Clin Med Res 2014;6:476-81. 